\title{
Pollution Status and Multimedia Fate Simulation of Phthalate Acid Esters (PAEs) in an Arid City
}

\author{
Fangfang Tian ${ }^{1}$, Yuyan Liu ${ }^{1 *}$, Cheng Liu ${ }^{1}$, Hongxin Gu${ }^{1}$, Haofeng Liu ${ }^{2}$ \\ ${ }^{1}$ Department of Chemistry and Applied Chemistry, Changii University, \\ Changji 831100, P. R. China \\ ${ }^{2}$ Changji Environmental Monitoring Station, \\ Changji 831100, P.R. China
}

Received: 26 May 2015

Accepted: 31 October 2015

\begin{abstract}
The content of four phthalate acid esters (PAEs) in air, soil, plants, organic films, and water of the arid city of Changji, China, was investigated and the concentration distribution and fate was simulated using a multimedia urban model (MUM). Analysis indicated that PAEs are ubiquitous environmental contaminants, with the dominant being DBP and DEHP. The mean PAE concentrations of air, soil, plants, organic films, and water was $5.54 \times 10^{-7} \mathrm{~g} / \mathrm{m}^{3}, 1.09 \times 10^{-2} \mathrm{~g} / \mathrm{m}^{3}, 6.57 \times 10^{-2} \mathrm{~g} / \mathrm{m}^{3}, 0.28 \mathrm{~g} / \mathrm{m}^{3}$, and $9.84 \times 10^{-2} \mathrm{~g} / \mathrm{m}^{3}$, respectively. By using MUM, we found that the total residues of PAEs in each environmental medium was $2.61 \times 10^{7} \mathrm{~g}$. The regularity of concentration distribution was organic films $>$ sediment $>$ plants $>$ water $>$ soil $>$ air, and the regularity of total amount distribution was air $>$ soil $>$ water $>$ sediment $>$ plants $>$ organic films. The regularity showed that air and soil were the main sink of PAEs (up to $99.59 \%$ of total mass). The reliability of the model was verified by the agreement between the measured and calculated concentrations.
\end{abstract}

Keywords: phthalic acid esters, concentration distribution, multimedia urban model, arid city

\section{Introduction}

Phthalate esters (PAEs) are industrially important chemicals widely applied as plasticizers and additives that improve the mechanical properties and flexibility of various products such as plastics, paints, and synthetic fibers. As PAEs are not chemically bound to the plastics, they can be released easily from products and migrate into the environment and hardly degrade $[1,2]$. Because of the widespread use of products containing PAEs, the residues of PAEs have been routinely detected in various matrices such as soil, water, air, and sediments [3, 4]. They are

*e-mail: 1228378007@qq.com extremely harmful to human and animal health and are shown to be carcinogenic and estrogenic [5-7], so PAEs have drawn great attention all over the world [8]. With the development of society, intensive production and human activities cause PAE content to increase in environmental media annually [9]. The present research about PAEs mostly focuses on a single medium [10], but PAEs have strong mobility in the environment [11], and then the macro environmental behavior of PAEs must be grasped. The weather and climate are special in an arid city, and they are the main factors affecting the transformation of environmental pollutants $[12,13]$. However, there was little research about PAE concentration distribution in multi-medium and the PAE multimedia fate model for an arid city was badly in need. Due to the fact that PAEs can 
cause problems even in very small concentrations, there is a need to develop a fast, simple, and reliable method for content determination of PAEs. The fugacity models have been shown to be valuable tools for investigaing multimedia environmental contamination of Pops [14, 15]. The model is unique in that it includes organic films on impervious surfaces as one of its compartments [16]. To understand and describe the environmental fates of contaminants, MUM (a level III fugacity model) was used to quantitatively determine the transfer and accumulation action.

Accordingly, the purpose of this research is to determine the levels of the four PAEs (DMP, DEP, DBP, and DEHP) targeted as priority pollutants by the U.S. Environmental Protection Agency in each environmental media and to simulate the concentration distribution and fate of the four PAEs. The model was verified by the agreement between the measured and calculated concentrations if it was reliable.

\section{Materials and Methods}

\section{Description of the Study Area}

Changji, in China on the north slope of the Tianshan Mountains and the southern margin of Junggar basin, is located at east longitude $86^{\circ} 24^{\prime}-87^{\circ} 37^{\prime}$, latitude $43^{\circ} 06^{\prime}$ $45^{\circ} 20^{\prime}$, which is in the center of Asia and Europe. It is a typical continental arid climate, and annual precipitation is only up to about $190 \mathrm{~mm}$. It is particularly cold in winter and hot in summer. The temperature difference is big between day and night.

\section{Sample Collection}

According to basic results of data analysis of the research and the function of land, the total three typical sites chosen to conduct research were Lanshan district (manufacturing), coach terminal station (traffic area), and Ninghe garden (residential area). There is a lack of surface water in an arid city, so People's Park Lake and Qinggeda Lake were chosen as water samples in this study. The samples were collected early each month from October to December, 2014, in air, soil, organic film, plants, and water, and every kind of sample was taken four times at each sampling point. Samples of air were collected continuously for about $24 \mathrm{~h}$ and the samplers were placed at a height of 1.5-2 $\mathrm{m}$ above ground level. Prior to sampling, the glass filters were baked in a muffle burner at $450^{\circ} \mathrm{C}$ for $4 \mathrm{~h}$ to remove the organic compounds that may exist in the filters. At each sampling site, five soil and plant sub-samples were collected from the surroundings of each site (within $100 \times 100 \mathrm{~m}^{2}$ ). The delicate task wipers were used to obtain the samples of surface film by wiping the impervious surfaces. The wipers were dried in a desiccator with a balance of $0.001 \mathrm{mg}$. Organic film is the thin film that coats impervious surfaces (windows, road surfaces, roofs) in urban areas, which can act as a source or sink of organic pollutants to the environment because of the organic content of the film. To prevent the pollution of the samples, plastic products were not contacted during the whole process.

\section{Instruments and Reagents}

We used a Shimadzu GC-2010 gas chromatograph, an RE-52AA rotatory evaporator, a Laoying 2030 median discharge intelligent TSP sampler, and an HY-CXJ highpower digital ultrasonic cleaner. PAE standards DMP, DEP, DBP, and DEHP were supplied by Dr. Ehrenstorfer (Augsburg, Germany). All organic solvents used were of analytical grade and redistilled using a glass system. Laboratory glassware was soaked overnight in $\mathrm{K} 2 \mathrm{CrO} 7 /$ $\mathrm{H} 2 \mathrm{SO} 4$ solution, washed with tap water and redistilled water, baked at $200^{\circ} \mathrm{C}$ for $1 \mathrm{~h}$, and then rinsed with acetone, acetone, and n-hexane.

\section{Analysis Method}

Air and organic film samples were put in a glassware dryer. All the soil, sediment, and plant samples washed by tap water and distilled water and placed in the shade to dry. When the samples were dried with a balance of $0.001 \mathrm{mg}$, soil and sediment were further sieved through a $0.154 \mathrm{~mm}$ sieve and plants were cut into fragments of $0.5-1 \mathrm{~cm}$ in length. All water samples were refrigerated and transported to the laboratory as soon as possible, where they were stored at $4^{\circ} \mathrm{C}$ before analysis (within $48 \mathrm{~h}$ ).

PAE extraction and purification: air, soil, plants, organic film, and sediment samples were Soxhletextracted with the mixture of acetone and n-hexane (1:1) for $10 \mathrm{~h}$ to extract the four target pollutants. Water samples were extracted by ultrasonic extraction with the mixture of acetone and $\mathrm{n}$-hexane $(1: 1)$ for $2 \mathrm{~h}$. All samples of extracted plants, soil, and water were purified by Florisil column. Content determination of PAEs was by gas chromatography-flame ionization detection (GC-FID).

The main working parameters of GC-FID were the injector, and ion source temperatures were maintained at $260^{\circ} \mathrm{C}$. The nitrogen carrier gas $(\geq 99.999 \%)$ was kept at a constant speed of $30 \mathrm{~mL} / \mathrm{min}$, hydrogen gas ( $\geq 99.999 \%)$ was kept at a constant speed of $40 \mathrm{~mL} / \mathrm{min}$, and air ( $\geq 99.999 \%$ ) was kept at a constant speed of $400 \mathrm{~mL} / \mathrm{min}$. $\mathrm{GC}$ oven temperature was initiated at $120^{\circ} \mathrm{C}$ for $4.0 \mathrm{~min}$, increased to $210^{\circ} \mathrm{C}$ at a rate of $10^{\circ} \mathrm{C} / \mathrm{min}$, held at $210^{\circ} \mathrm{C}$ for $4.0 \mathrm{~min}$, then increased at $5^{\circ} \mathrm{C} / \mathrm{min}$ to $220^{\circ} \mathrm{C}$ and held for $4.0 \mathrm{~min}$, and finally ramped up $3^{\circ} \mathrm{C} / \mathrm{min}$ to $260^{\circ} \mathrm{C}$ and held for $2 \mathrm{~min}$. The $1.0 \mu \mathrm{L}$ extracts were injected into $\mathrm{GC}$ in splitless mode with a split ratio of 15:1.

To avoid contamination of the samples by laboratory equipment during handling and analysis, all glassware was washed and rinsed in chromic acid and subsequently heated at $400^{\circ} \mathrm{C}$ for $10 \mathrm{~h}$. For each batch of six field samples, a procedural blank was processed. No target PAEs were found in blank tests. Additionally, surrogate standards were added to each sample, which produced the following recoveries: DMP: 88\% 94\%; DEP: 90\% 102\%; DBP: 
Table 1. PAE concentrations in sampling events.

\begin{tabular}{|c|c|c|c|c|c|}
\hline \multirow{2}{*}{ Sites } & \multirow{2}{*}{ Medium } & \multicolumn{4}{|c|}{ PAE concentrations $\left(\mathrm{g} / \mathrm{m}^{3}\right)$} \\
\hline & & DMP & DEP & DBP & DEHP \\
\hline \multirow{4}{*}{$\begin{array}{l}\text { Coach Terminal } \\
\text { Station }\end{array}$} & air & $1.42 \times 10^{-8}$ & $2.53 \times 10^{-8}$ & $2.00 \times 10^{-7}$ & $3.78 \times 10^{-7}$ \\
\hline & soil & $4.51 \times 10^{-3}$ & $2.15 \times 10^{-3}$ & $2.41 \times 10^{-3}$ & $3.45 \times 10^{-3}$ \\
\hline & plants & $1.53 \times 10^{-2}$ & $8.5 \times 10^{-3}$ & $4.00 \times 10^{-2}$ & $1.28 \times 10^{-2}$ \\
\hline & organic film & $6.07 \times 10^{-2}$ & $3.44 \times 10^{-2}$ & $6.15 \times 10^{-2}$ & $5.99 \times 10^{-2}$ \\
\hline \multirow{4}{*}{ Lanshan district } & air & $1.67 \times 10^{-8}$ & $3.44 \times 10^{-8}$ & $3.15 \times 10^{-7}$ & $4.92 \times 10^{-7}$ \\
\hline & soil & $1.62 \times 10^{-3}$ & $1.03 \times 10^{-3}$ & $4.77 \times 10^{-3}$ & $3.71 \times 10^{-3}$ \\
\hline & plants & $8.08 \times 10^{-3}$ & $7.23 \times 10^{-3}$ & $5.44 \times 10^{-2}$ & $1.79 \times 10^{-2}$ \\
\hline & organic film & $7.76 \times 10^{-2}$ & $1.7 \times 10^{-2}$ & 0.23 & 0.12 \\
\hline \multirow{4}{*}{ NingHe garden } & air & $1.23 \times 10^{-8}$ & $2.00 \times 10^{-8}$ & $5.35 \times 10^{-8}$ & $9.90 \times 10^{-8}$ \\
\hline & soil & $2.92 \times 10^{-3}$ & $2.04 \times 10^{-3}$ & $2.17 \times 10^{-3}$ & $1.80 \times 10^{-3}$ \\
\hline & plants & $6.46 \times 10^{-3}$ & $6.55 \times 10^{-3}$ & $7.91 \times 10^{-3}$ & $1.19 \times 10^{-2}$ \\
\hline & organic film & $5.90 \times 10^{-2}$ & $2.71 \times 10^{-2}$ & $5.25 \times 10^{-2}$ & $4.92 \times 10^{-2}$ \\
\hline People's Park & water & 0 & $8.3 \times 10^{-4}$ & $5.83 \times 10^{-2}$ & $3.39 \times 10^{-2}$ \\
\hline Qinggeda Lake & water & $1.43 \times 10^{-2}$ & 0 & $4.78 \times 10^{-2}$ & $4.17 \times 10^{-2}$ \\
\hline
\end{tabular}
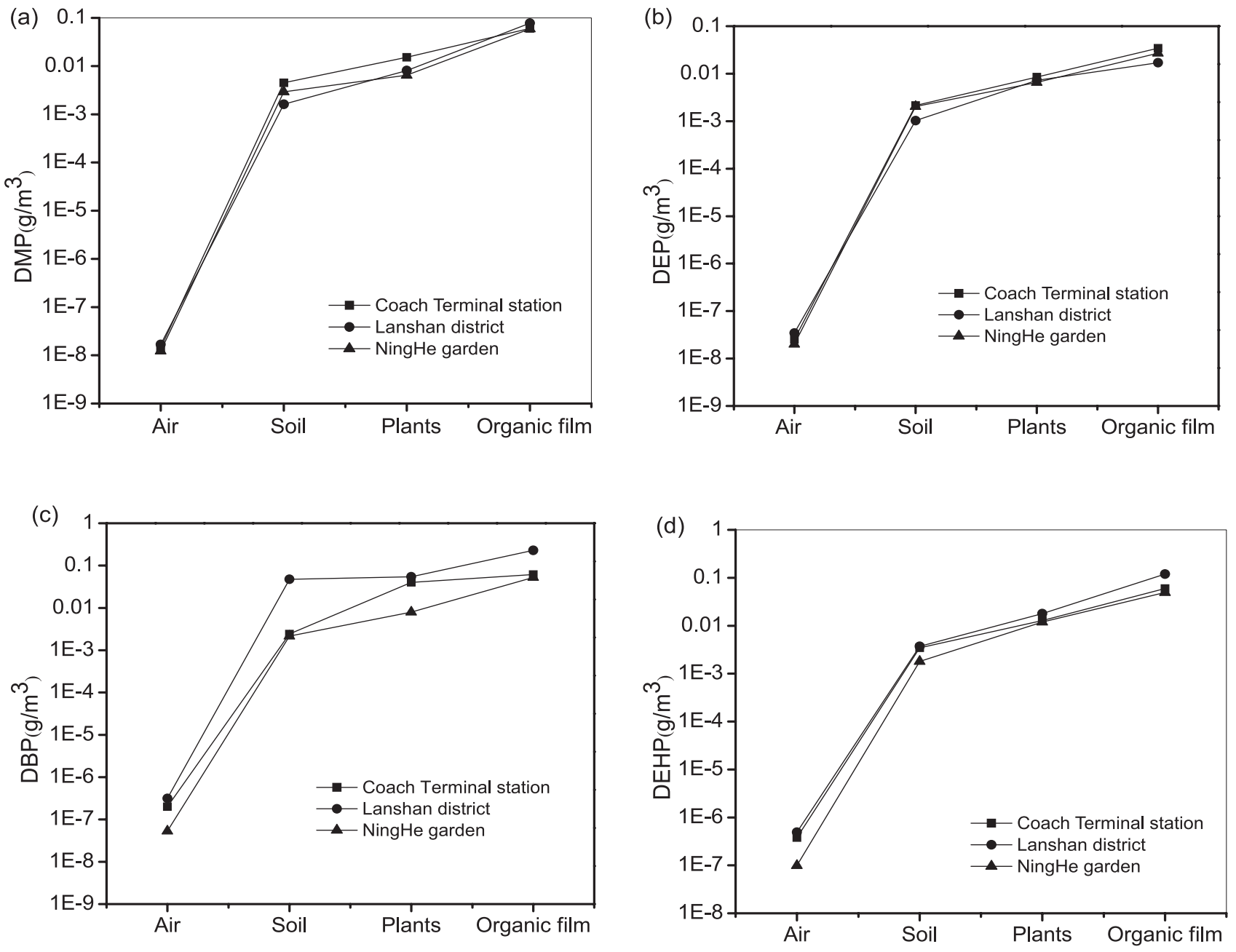

Fig. 1. Concentrations of PAEs in multimedia environment: (a) DMP $\left(\mathrm{g} / \mathrm{m}^{3}\right)$, (b) $\operatorname{DEP}\left(\mathrm{g} / \mathrm{m}^{3}\right),(\mathrm{c}) \operatorname{DBP}\left(\mathrm{g} / \mathrm{m}^{3}\right),(\mathrm{d}) \operatorname{DEHP}\left(\mathrm{g} / \mathrm{m}^{3}\right)$. 
80\% 96\%; BBP: 95\% 108\%; and DEHP: 92\% 107\%. The method had good liner relationship and the correlation coefficient of four PAEs were all more than 0.996. The limit detection of DMP, DEP, DBP, and DEHP was $1.18,1.43,1.52$, and $0.888 \mu \mathrm{g} / \mathrm{mL}$, respectively. Repeat measurement of mixed standard solution of $50 \mu \mathrm{g} / \mathrm{mL}$ was made five times to test the precision of methods. The results showed that the relative standard deviations of the method were all $<5 \%$ for each case, which were $2.0 \%$, $1.6 \%, 2.2 \%$, and $4.2 \%$, respectively. In order to ensure the reliability of experimental data, the same samples were measured in parallel, and deviation of not more than $5 \%$.

\section{Results and Discussion}

\section{PAE Concentrations in an Urban Environment}

Combined with Table 1 and Fig. 1, the results indicated that the average concentrations of the four PAEs were $5.54 \times 10^{-7}\left(1.85 \times 10^{-7} \sim 8.58 \times 10^{-7}\right) \mathrm{g} / \mathrm{m}^{3}$ in air, $1.09 \times 10^{-2}$ $\left(6.86 \times 10^{-3} \sim 1.32 \times 10^{-2}\right) \mathrm{g} / \mathrm{m}^{3}$ in soil, $6.57 \times 10^{-2}(4.45 \times 10$ $\left.2 \sim 8.76 \times 10^{-2}\right) \mathrm{g} / \mathrm{m}^{3}$ in plants, $0.28(0.19 \sim 0.44) \mathrm{g} / \mathrm{m}^{3}$ in organic film, and $0.28(0.19 \sim 0.44) \mathrm{g} / \mathrm{m}^{3}$ in water. The regularity of concentration distribution in the five media was organic films $>$ sedimen $t>$ plants $>$ water $>$ soil $>$ air.

The mean concentrations of DMP, DEP, DBP, and DEHP in the three sampling sites were $9.80 \times 10^{-2}(6.84 \times$ $\left.10^{-2} \sim 0.14\right) \mathrm{g} / \mathrm{m}^{3}, 3.53 \times 10^{-2}\left(2.53 \times 10^{-2} \sim 4.51 \times 10^{-2}\right) \mathrm{g} / \mathrm{m}^{3}$, $0.15\left(7.16 \times 10^{-2} \sim 0.29\right) \mathrm{g} / \mathrm{m}^{3}$, and $9.36 \times 10^{-2}\left(6.46 \times 10^{-2}\right.$ $\sim 0.14) \mathrm{g} / \mathrm{m}^{3}$, respectively (Table 1). Among which, the highest concentrations of DMP and DEP appeared in coach terminal station. That is because the two PAEs are of low molecular weight and are usually used in cosmetics and personal care products, such as perfumes and nail polishes [17], while the coach terminal station is located in the city center and the population density is high. Hence the great amount of consumption of daily necessities leads to higher DMP and DEP contents in the environment. The highest concentrations of DBP and DEHP appeared in Lanshan district as the two are high-to mid-molecular-weight PAEs that are widely used as plasticizers to improve the flexibility and workability of polymeric materials [11]. The polyvinyl chloride (PVC) production containing high molecular-weight PAEs [18] produced in Lanshan district resulted in higher DBP and DEHP contents in the environment.

The concentration percentages of DMP, DEP, DBP, and DEHP were $2.60 \%, 4.40 \%, 34 \%$, and $59 \%$, respectively, in air; $28 \%, 16 \%, 28.6 \%$, and $27.4 \%$, respectively in soil; $15.1 \%, 11.3 \%, 52 \%$, and $21.6 \%$, respectively, in plants; $23 \%, 8.7 \%, 41 \%$, and $27.3 \%$, respectively, in organic film; and $7.3 \%, 0.4 \%, 53.9 \%$, and $38.4 \%$, respectively, in water. The result suggested that DBP and DEHP were the dominant components of the PAEs analyzed, which is consistent with the use of similar commercial PAEs around the world [19].

The concentrations of PAEs in this study were lower than those in other areas $[20,21]$, and there was significant difference of PAE content in soil and water when compared with the results of similar research [22]. This may be attributed to little human interference with the environment because of the relatively sparse population in an arid city. Additionally, the sources of PAEs in soil of city are diffusion, dry and wet deposition of air and canopy drip, wax erosion, and plant litter [23], while the lack of rain and low coverage of vegetation cause low concentrations of PAEs in an arid city.

\section{Concentration Distribution and Fate Simulation of PAEs in Multimedia}

\section{The Model}

Based on MUM [24] and combined with the geographical and meteorological information and other conditions of Changji City, the Multimedia fate Model of Level III steady-state was constructed. The environmental medium of Changji was divided into six main phases in this study: air (A), soil (S), organic film (F), plants (P), water (W), and sediment (Sed). According to the steady state assumption and mass balance relations, mass balance equations can be established for the main phase below [25]:

$$
\begin{gathered}
\text { Air: } E_{A}+D_{W-A} f_{W}+D_{S-A} f_{S}+D_{V-A} f_{V}+D_{F-A} f_{F}+G_{A} C_{A}= \\
f_{A}\left(D_{A-W}+D_{A-S}+D_{A-V}+D_{R(A)}+D_{A(A)}\right) \\
\text { Water: } E_{W}+D_{A-W} f_{A}+D_{S-A} f_{S}+D_{S e d-W} f_{S e d}+D_{F-W} f_{F}= \\
f_{W}\left(D_{W-A}+D_{W-S}+D_{R(W)}\right) \\
\text { Soil: } D_{A-S} f_{A}+D_{V-S} f_{V}=f_{S}\left(D_{S-A}+D_{V-S}+D_{R(S)}\right) \\
\text { Sediment: } D_{W-S e d} f_{W}=f_{S e d}\left(D_{S e d-W}+D_{R(S e d)}\right) \\
\text { Organic film: } D_{F-A} f_{A}=f_{F}\left(D_{F-A}+D_{F-W}+D_{R(F)}\right) \\
\text { Plants: } D_{A-P} f_{A}=f_{P}\left(D_{P-A}+D_{P-S}+D_{R(P)}\right)
\end{gathered}
$$

...where $E$ shows emissions velocity, mol/h; $D$ shows the transfer velocity of different medias, $\mathrm{mol} /(\mathrm{Pa} \cdot \mathrm{h}) ; D_{\mathrm{R}}$ shows degradation velocity, $\mathrm{mol} /(\mathrm{Pa} \cdot \mathrm{h}) ; D_{\mathrm{A}}$ shows the advective transport velocity, $\mathrm{mol} /(\mathrm{Pa} \cdot \mathrm{h}) ; G_{\mathrm{A}}$ shows the advective output velocity, $\mathrm{m}^{3} / \mathrm{h} ; C_{A}$ shows the advective input concentrations; and $f$ shows fugacity, $\mathrm{Pa}$.

\section{Progress Model Parameters}

The release of PAEs into this system is consistent with advective flow (i.e., water and air flow with concentrations originating from outside the modelled domain) and indirect emissions (paint, plastic film, insect repellent volatilization) [26]. The exchange processes between different environmental medias include gas-water, gassoil (dry and wet deposition, diffusion), rain washing, landmark runoff, diffusion between water and sediment, sedimentation and resuspension, etc. The output processes 
Table 2. Environmental parameter values.

\begin{tabular}{|c|c|c|c|c|c|c|}
\hline & Air & Water & Soil & Sediment & Plant & film \\
\hline Surface area $\left(\mathrm{A}, \mathrm{m}^{2}\right)$ & $8.22 \times 10^{9 a}$ & $5.36 \times 10^{5 a}$ & $8.10 \times 10^{8 a}$ & $5.36 \times 10^{5 a}$ & $1.56 \times 10^{7 a}$ & $1.75 \times 10^{8 \mathrm{a}}$ \\
\hline Depth $(\mathrm{d}, \mathrm{m})$ & $1000^{c}$ & $1.50^{\mathrm{b}}$ & $0.05^{\mathrm{c}}$ & $0.05^{\mathrm{c}}$ & $2.00 \times 10^{-4 c}$ & $7.00 \times 10^{-8 c}$ \\
\hline Volume $\left(\mathrm{V}, \mathrm{m}^{3}\right)$ & $8.22 \times 10^{12}$ & $8.04 \times 10^{5}$ & $4.05 \times 10^{8}$ & $2.68 \times 10^{4}$ & $3.12 \times 10^{3}$ & 12.25 \\
\hline Density $\left(\rho, \mathrm{kg} / \mathrm{m}^{3}\right)$ & 1.19 & 1000 & $2650^{\mathrm{d}}$ & $2140^{\mathrm{e}}$ & $850^{\mathrm{f}}$ & $8.2 \times 10^{2 c}$ \\
\hline Organic carbon content(foc) & $0.02^{g}$ & $0.02^{\mathrm{h}}$ & 0.02 & $0.01^{\mathrm{h}}$ & $0.02^{\mathrm{c}}$ & $0.74^{c}$ \\
\hline $\begin{array}{l}\text { Volume ratio of vapor phase } \\
\qquad\left(\mathrm{V}_{\mathrm{a}}\right)\end{array}$ & 1.00 & - & $0.20^{\mathrm{c}}$ & - & $0.18^{c}$ & - \\
\hline $\begin{array}{l}\text { Volume ratio of water phase } \\
\qquad\left(\mathrm{V}_{\mathrm{w}}\right)\end{array}$ & - & 1 & $0.30^{c}$ & $0.30^{\mathrm{g}}$ & $0.80^{\mathrm{c}}$ & - \\
\hline $\begin{array}{l}\text { Volume ratio of particle } \\
\qquad\left(\mathrm{V}_{\text {part }}\right)\end{array}$ & $1.04 \times 10^{-10 \mathrm{~g}}$ & $5.26 \times 10^{-5 g}$ & $0.50^{\mathrm{c}}$ & $0.70^{\mathrm{c}}$ & - & $0.30^{c}$ \\
\hline Volume ratio of esters $\left(\mathrm{V}_{\text {lipid }}\right)$ & - & - & - & - & $0.02^{\mathrm{c}}$ & $0.30^{\mathrm{c}}$ \\
\hline
\end{tabular}

Note: a. From National Knowledge Infrastructure; b. From come from (Wang., 2010); c. From (Dionmand et al., 2001); d. From (Liu et al., 2006); e.From (Liu et al., 2014); f. From (Zhao et al., 2011); g. From (Mackay, 2001); h. From (Law., 1996); “---”represents not detected, which can be neglected when making model calculations.

include degradation loss in different media and the output of air flow. Water flows slowly in an arid city, so the advection output of water was not considered.

Input parameters are the simulation area environment parameter values (Table 2) and physical-chemical properties of PAEs. A small number of parameters were used for reference, which were from adjacent areas because of the difficulties in data acquisition. The measured parameters are the average concentrations in each environmental media except sediment, which was from Liu et al. (2014) [8]. The environmental concentration in the model is the average concentration of all PAEs calculated by $\mathrm{C}=\mathrm{Zf}[16]$ :

\section{Simulation Distribution of PAEs}

According to statistical analyses (Table 3), when the system was in steady-state, simulation results inferred that the mass concentrations of PAEs were $1.69 \times 10^{-6} \mathrm{~g} / \mathrm{m}^{3}$ in air, $0.030 \mathrm{~g} / \mathrm{m}^{3}$ in soil, $0.20 \mathrm{~g} / \mathrm{m}^{3}$ in plants, $2.91 \mathrm{~g} / \mathrm{m}^{3}$ in organic film, $0.10 \mathrm{~g} / \mathrm{m}^{3}$ in water, and $0.88 \mathrm{~g} / \mathrm{m}^{3}$ in sediment. The mass concentrations ranged from organic film and sediment, followed by Plants, water, soil, and air.

The simulation of the total inferred that the total amount of PAEs in the environment was $2.61 \times 10^{7} \mathrm{~g}$, and the distribution in the default urban environment was $1.39 \times 10^{7} \mathrm{~g}, 1.22 \times 10^{7} \mathrm{~g}, 619.19 \mathrm{~g}, 35.65 \mathrm{~g}, 8.19 \times 10^{4} \mathrm{~g}$, and $2.35 \times 10^{4} \mathrm{~g}$. Then the distribution law was air $>$ soil $>$ water $>$ sediment $>$ plants $>$ organic films. It was obvious that PAEs accumulated in air and soil mainly, accounting for nearly $99.59 \%$ of the total residual amount of PAEs in the urban environment. Different from air, (though the residual quantity of PAEs was less), the concentration was highest among all the media. That was because organic film has a strong adsorption capacity to PAEs with great specific surface area $[26,27]$. Moreover, washing during precipitation events was a significant loss approach for organic film, while it is dry and lack of rain all the year round in arid city, and PAEs can accumulate efficiently on organic film.

Table 3. Calculated concentrations of PAEs.

\begin{tabular}{|c|c|c|c|c|c|}
\hline \multirow{2}{*}{ Medium } & \multicolumn{4}{|c|}{ PAE concentrations $\left(\mathrm{g} / \mathrm{m}^{3}\right)$} & \multirow{2}{*}{$\begin{array}{c}\text { Total content in } \\
\text { environment }(\mathrm{g})\end{array}$} \\
\cline { 2 - 5 } & DMP & DEP & DBP & DEHP & $1.39 \times 10^{7}$ \\
\hline air & $7.85 \times 10^{-8}$ & $1.89 \times 10^{-8}$ & $4.04 \times 10^{-8}$ & $1.55 \times 10^{-6}$ & $1.22 \times 10^{7}$ \\
\hline soil & $2.3 \times 10^{-3}$ & $7.36 \times 10^{-5}$ & $4.34 \times 10^{-3}$ & $2.23 \times 10^{-2}$ & 619.16 \\
\hline plants & 0.014 & 0.02 & $4.45 \times 10^{-3}$ & 0.16 & 35.65 \\
\hline film & 0.30 & 0.37 & 0.24 & 2.00 & $8.19 \times 10^{4}$ \\
\hline water & 0.031 & $6 \times 10^{-4}$ & $3.48 \times 10^{-3}$ & $6.68 \times 10^{-2}$ & $2.35 \times 10^{4}$ \\
\hline sediment & 0.026 & 0.011 & $5.26 \times 10^{-2}$ & 0.79 & \\
\hline
\end{tabular}




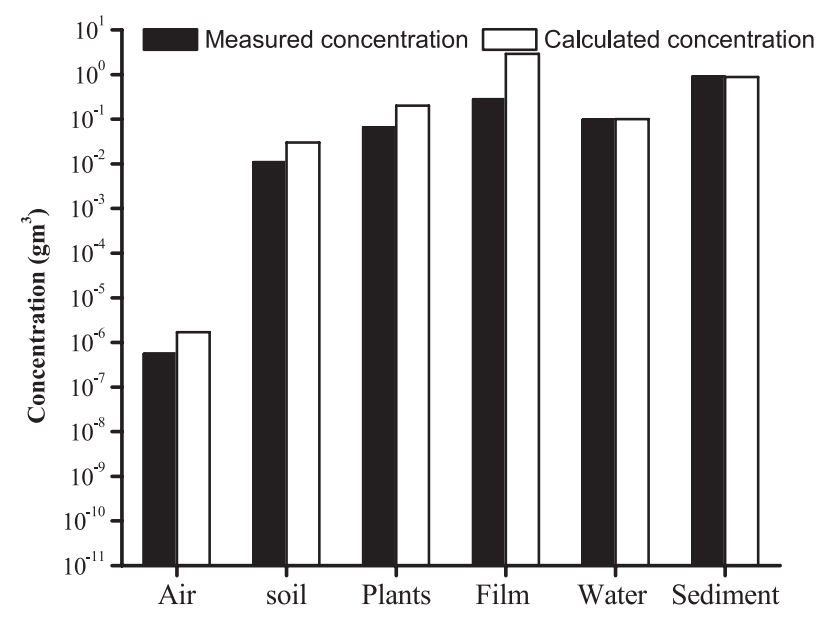

Fig. 2. Comparision between measured and calculated concentrations of PAEs.

\section{Model Validation}

In order to verify the reliability of the model, the measured and calculated concentrations were compared with each other. The study simulated the multimedia fate of PAEs in 2014 due to the PAE content data of each environmental media in literature were more than ever in this year. The measured parameters are the average concentrations of air, soil, plants, organic film, and water in this study, while the sediment data was from Liu et al. (2014) [8]. The comparison results indicated that calculated values were higher than the measured ones, which might be contributed to less interference by people in an arid city where it was particularly cold in winter. Additionally, it was suggested that the calculated values of PAEs with high molecular weight appeared higher, which may associate with the degradation rate constant [21]. However, the mass of DBP and DEHP accounted for $77 \%$ in the study area, so the calculated values were higher than the measured ones in every environmental medium. Because of the complexity of the urban district of Changji City, the model parameters inevitably include uncertainties, then the output of the model is only an approximation of the fate of pollutants. It was considered reasonable when simulation results and the measured values were within the same order of magnitude. Fig. 2 showed that the value difference between the calculated and the measured was less than a logarithmic unit in all environmental media except organic film. Therefore, the model could be firmly believed to be effective for the PAEs in an arid city.

Compared with other organic materials $[18,28]$, the MUM model perfectly simulates the multimedia fate characteristics of PAEs in an arid city. The value difference between the calculated and the measured PAEs was more than a logarithmic unit and was directly related to the high octanol-air partition coefficient $\mathrm{K}_{\mathrm{OA}}$ values that govern airfilm and air-soil exchanged low vapor pressure [29] used in this study. It is obvious that better accuracy of MUM depends on higher reliable parameters of the environments in the study area.

\section{Conclusions}

This study has provided the first data on the pollution status of PAEs in the arid region of northwest China. The data presented here establish a baseline for future monitoring and management of these compounds in this area. The analysis results indicated that PAEs are ubiquitous environmental contaminants dominated DBP and DEHP. The mean PAE concentrations of air, soil, plants, organic films, and water was $5.54 \times 10^{-7} \mathrm{~g} / \mathrm{m}^{3}, 1.09 \times 10^{-2} \mathrm{~g} / \mathrm{m}^{3}$, $6.57 \times 10^{-2} \mathrm{~g} / \mathrm{m}^{3}, 0.28 \mathrm{~g} / \mathrm{m}^{3}$, and $9.84 \times 10^{-2} \mathrm{~g} / \mathrm{m}^{3}$, respectively. The concentrations of PAEs in this study were lower than those in other areas, and this may be attributed to having little human interference with the environment because of relatively sparse population in the arid city.

The reliability of the model was verified by the agreement between the measured and calculated concentrations. By using MUM, it was shown that the total residues of PAEs in each environmental media was $2.61 \times 10^{7} \mathrm{~g}$. The concentration distribution was $2.91 \mathrm{~g} / \mathrm{m}^{3}$ in organic films, $0.88 \mathrm{~g} / \mathrm{m}^{3}$ in sediment, $0.20 \mathrm{~g} / \mathrm{m}^{3}$ in plants, $0.10 \mathrm{~g} / \mathrm{m}^{3}$ in water, $2.90 \times 10-2 \mathrm{~g} / \mathrm{m}^{3}$ in soil, $1.69 \times 10-6 \mathrm{~g} / \mathrm{m}^{3}$ in air, repectively.

The total amount distribution was $1.39 \times 107 \mathrm{~g}$ in air, $1.22 \times 107 \mathrm{~g}$ in soil, $8.19 \times 104 \mathrm{~g}$ in water, $2.35 \times 104 \mathrm{~g}$ in sediment, $619.16 \mathrm{~g}$ in plants, $35.65 \mathrm{~g}$ in organic films.

The regularity showed that air and soil were the main sink of PAEs (up to $99.59 \%$ of total mass).

The agreement of calculated and measured values has verified the reliability of MUM and indicates that the model can be applied to the simulation of PAE multimedia fate in an arid city.

\section{Acknowledgements}

This research was supported by the Natural Science Foundation of Xinjiang Uygur Autonomous Region (No. 2013211A034).

\section{References}

1. COUSINS A.P., HOLMGREN T., REMBERGER M. Emissions of two phthalate esters and BDE 209 to indoor air and their impact on urban air quality. Sci. Total Environ. 470-471, 527, 2014.

2. SARAVANABHAVAN G., WALKER M., GUAY M., AYLWARD L. Urinary excretion and daily intake rates of diethyl phthalate in the general Canadian population. Sci. Total Environ. 500-501, 191, 2014.

3. SUN J.Q., HUANG J., ZHANG A.P., LIU W.P., CHENG W.W. Occurrence of phthalate esters in sediments in Qiantang River, China and inference with urbanization and river flow regime. J. Hazard. Mater. 248, 142, 2013.

4. LIU X.W., SHI J.H., BO T., ZHANG H.,WU W., CHEN Q.C., ZHAN X.M. Occurrence of phthalic acid esters in source waters: a nationwide survey in China during the period of 2009-2012. Environ. Pollut. 184, 262, 2014.

5. FIERENS T., SERVAES K., VAN HOLDERBEK M., GEERTS L., DE HENAUW S., SIOEN,I., VANERMEN 
G. Analysis of phthalates in food products and packaging materials sold on the Belgian market. Food Chem. Toxicol. 50, 2575, 2012.

6. KERESZTES S., TATÁR E., CZÉGÉNY Z., ZÁRAY G., MIHUCZ V.G. Study on the leaching of phthalates from polyethylene terephthalate bottles into mineral water. Sci. Total Environ. 458-460, 451, 2013.

7. ZOLFAGHARI M., DROGUI P., SEYHI B., BRAR S.K., BUELNA G., DUBE R. Occurrence, fate and effects of Di (2-ethylhexyl) phthalate in wastewater treatment plants: A review. Environ. Pollut. 194, 281, 2014.

8. LIU Y.Y., GU H.X., ZENG H.H., ZENG Y.M., MIAO J., CHENG J.W. The distribution characteristics of PAEs in landscape waters sediment of WuChang urban agglomeration. Earth and Environment 42, 620, 2014.

9. CHI J., GAO J. Effects of Potamogeton crispus L. - bacteria interactions on the removal of phthalate acid esters from surface water. Chemosphere. 119, 59, 2015.

10. ZHANG L.B., WANG F.M., JI Y. Q., JIAO J., ZOU D.K., LIU L.L., SHAN C.Y., BAI Z.P., SUN Z. R. Phthalate esters (PAEs) in indoor PM10/PM2.5 and human exposure to PAEs via inhalation of indoor air in Tianjin, China. Atmos. Environ. 85, 139, 2014.

11. NIU L.L., XU Y., XU C., YUN L.X., LIU W.P. Status of phthalate esters contamination in agricultural soils across China and associated health risks Environ. Pollut. 195, 16, 2014.

12. LIU Y.Y., LIU Y.J. Effect of climate conditions in arid area on accumulation of $\mathrm{Pd}, \mathrm{Rh}$ in dust and soil from road environment. China Environ. Sci. 31, 1528, 2011.

13. CARTER J.G., CAVAN G., CONNELLY A., GUY, S., HANDLEY J., KAZMIERCZAK A. Climate change and the city: Building capacity for urban adaptation Original Research Article. Prog. Plan. 95, 1, 2015.

14. 14. DYCK R., SADIQ R., RODRIGUEZ M.J., SIMARD S., TARDIF R. Trihalomethane exposure in indoor swimming pools: A level III fugacity model. Water Res. 45, 5084, 2011.

15. TREMOLADA P., GUAZZONI NICCOLÒ., PAROLINI M., ROSSARO B., BIGNAZZI M. M., BINELLI A. Predicting PCB concentrations in cowmilk: validation of a fugacity model in high-mountain pasture conditions. Sci. Total Environ. 487, 471, 2014.

16. DIONMAND M.L., PRIEME D.A., LAW N.L. Developing a multimedia model of chemical dynamics in an urban area. Chemosphere. 44, 1755, 2001.

17. KONIECKI D., WANG R., MOODY R.P., ZHU J.P. Phthalates in cosmetic and personal care products: concentrations and possible dermal exposure. Environ. Res. 111, 329, 2011.
18. PRADEEP S., BENJAMIN S. Mycelial fungi completely remediate di (2-ethylhexyl) phthalate, the hazardous plasticizer in PVC blood storage bag. J. Hazard. Mater. 235236, 69, 2012.

19. XU Y., COHEN HUBAL E.A., CLAUSEN P.A., LITTLE J.C. Predicting residential exposure to phthalate plasticizer emitted from vinyl flooring: a mechanistic analysis. Environ. Sci. Technol. 43, 2374, 2009.

20. HU X.G., ZHOU Q.X., LUO Y. Occurrence and source analysis of typical veterinary antibiotics in manure, soil, vegetables and groundwater from organic vegetable bases, northern China. Environ. Pollut. 158, 2992, 2010.

21. KONG S.F., JI Y.Q., LIU L.L., CHEN L., ZHAO X.Y., WANG J.J., BAI Z.P., SUN Z.R. Diversities of phthalate esters in suburban agricultural soils and wasteland soil appeared with urbanization in China. Environ. Pollut. 170, 161, 2012.

22. CUI X.H., LI B.H., CHEN H.H., WAN P.Q. A review of phthalic acid esters contamination and sorption in soil and sediment, China. Ecol. Environ. 19, 472, 2010.

23. RHIND S.M., KYLE C.E., KERR C., OSPREY M., ZHANG Z.L., DUFF E.I., LILLY A., NOLAN A., HUDSON G., TOWERS W., BELL J., COULL M., MCKENZIE C. Concentrations and geographic distribution of selected organic pollutants in Scottish surface soils. Environ. Pollut. 182, 15, 2013.

24. PRIEMER D.A., DIONMAND M. L. Application of the multimedia urban model to compare the fate of SOCs in an urban and forested watershed. Environ. Sci. Technol. 36, 1004, 2001.

25. MACKAY D. Multimedia environmental models: The fugacity Approach. Chelsea: Lewis Pub. 2001.

26. CSISZAR S.A., DIAMOND M.L., THIBODEAUX L.J. Modeling urban films using a dynamic multimedia fugacity model. Chemosphere. 87, 1024, 2012.

27. WU Y.H., SI Y.B., ZHOU D.M., GAO J. Adsorption of diethyl phthalate ester to clay minerals. Chemosphere 119, 690, 2015.

28. KWAMENAN.A., CLARKE J.P., KAHAN T.F., DIAMOND M.L., DONALDSON D.J. Assessing the importance of heterogeneous reactions of polycyclic aromatic hydrocarbons in the urban atmosphere using the Multimedia Urban Model. Atmos. Environ. 41, 37, 2007.

29. BEYER A., WANIA F., GOUIN T., MACKAY D., MATTHIES M. Selecting internally consistent physicochemical properties of organic compounds. Environ. Toxicol. Chem. 21, 941, 2002. 
